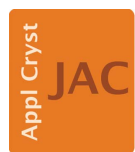

JOURNAL OF

APPLIED

CRYSTALLOGRAPHY

ISSN 1600-5767

Received 7 November 2017

Accepted 7 November 2017

Keywords: bond-valence sums; bond-valence sum mapping; bond-valence energy landscape; isosurfaces; automation; ion-conduction pathways; topology; CIF; Perl; Materials Studio

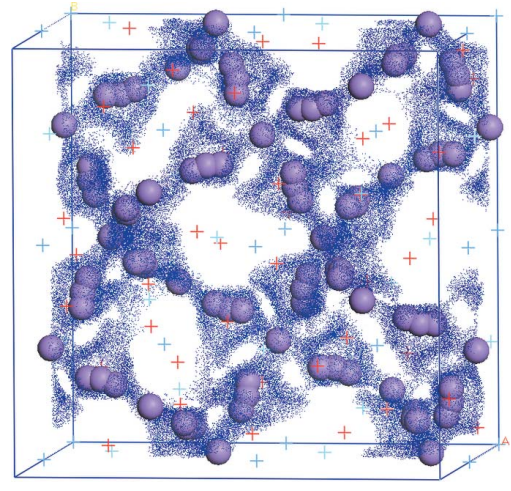

C 2017 International Union of Crystallography

\section{DBVSMAPPER: a program for automatically generating bond-valence sum landscapes. Corrigendum}

\author{
Matthew Sale* and Maxim Avdeev*
}

Bragg Institute, Australian Nuclear Science and Technology Organisation (ANSTO), New Illawarra Road, Lucas Heights, New South Wales 2234, Australia.*Correspondence e-mail: mts@ansto.gov.au, max@ansto.gov.au

An equation in the article by Sale \& Avdeev [J. Appl. Cryst. (2012), 45, 10541056] is corrected.

In the article by Sale \& Avdeev (2012), some of the brackets in equation (2) are misplaced. Equation (2) in the original article reads as follows:

$$
\mathrm{BVEL}_{+/-}=\sum_{j=1}^{N}\left(m_{j} D_{0}\left\{\exp \left[\alpha\left(R_{\min }-d_{j}\right)\right]-1\right\}^{2}-1\right) \text {. }
$$

This should be changed to the following:

$$
\mathrm{BVEL}_{+/-}=\sum_{j=1}^{N}\left[m_{j} D_{0}\left(\left\{\exp \left[\alpha\left(R_{\min }-d_{j}\right)\right]-1\right\}^{2}-1\right)\right] \text {. }
$$

The original code does not have this problem. Therefore, the figures and calculated results are not affected.

\section{References}

Sale, M. \& Avdeev, M. (2012). J. Appl. Cryst. 45, 1054-1056. 